\section{Is chemistry}

\section{physics?}

\author{
Kostas Gavroglu
}

From Chemical Philosophy to Theoretical Chemistry: Dynamics of Matter and Dynamics of Disciplines, 1800-1950. By Mary Joe Nye. University of California Press: 1994. Pp. 328. \$48.

IN 1929, Paul Dirac declared that "the underlying physical laws for the mathematical theory of a large part of physics and the whole of chemistry are completely known". It seemed that the only thing left for chemists to do was to devise methods for carrying out the calculations. His optimism is reminiscent of the 'grand scheme' proposed by Laplace at the end of the eighteenth century or, more recently, talk about 'theories of everything'. In these pronouncements there is a touch of arrogance, a product, no doubt, of the phenomenal success of quantum mechanics (Dirac), Newtonian mechanics (Laplace) or gauge theories. But arrogance in science, just as in politics, tends to obscure the historical nature of problems. The statements adopt a strongly reductionist view of the world, implying that, immense mathematical difficulties notwithstanding, the variety and complexity of entities and phenomena are constructible from and hence explainable in terms of 'basic entities' and underlying laws. Dirac's pronouncement had a further, rather paralysing, implication: that chemistry, in the final analysis, is physics. It was not the first time that chemistry was portrayed as a branch of physics.

Mary Joe Nye attempts to trace the history of this ambivalent attitude towards chemistry during the past two centuries. The history of chemistry has been marked by a Sisyphean curse: the more chemistry resembled physics, the more it was regarded as being a 'true' science; but the more it gained such prestige, the more it lost its identity, and the less autonomous it became. Nye directly addresses the question of whether chemistry is reducible to physics, but she also examines the issue by studying the formation of the boundaries of physical chemistry, chemical physics, theoretical chemistry and quantum chemistry. She convincingly demonstrates that the construction of the identity of theoretical chemistry and the drawing of disciplinary boundaries were due to a network of factors. She examines genealogy and historical mythology at the beginning of each discipline; archetypal language and imagery; codified practices and rituals; the establishment of institutions based on rights and responsibilities; and external recognition, shared values and unsolved problems. Before turning to specific case studies, she discusses chemical epistemology, and language and imagery in nineteenth-century chemistry.

Nye is committed to the view that research schools are the most convenient units for the study of discipline formation, so she concentrates on the Paris and London-Manchester schools of theoretical organic chemistry between 1880 and 1930 , on Christopher Ingold's attempt to integrate physical and organic chemistry and on the development of quantum chemistry in Britain and America. She steers readers through a maze of details and arguments to conclude that theoretical chemistry slowly acquired its autonomy as a result of a complex interplay of the convergent and divergent practices of individuals and schools. The establishment of physical chemistry and quantum chemistry was due not merely to the successful application of physical methods and theories to chemical problems, but also to a series of legitimizing procedures.

Two aspects in specifying the identity of disciplines deserve separate consideration; their significance is, I think, played down in Nye's treatment. The first is the role of disputes, which can reveal subtle undercurrents in the processes of legitimizing new theories, defining boundaries and inaugurating a particular ethos for each discipline. The second aspect is the meaning of theory in chemistry, a discipline in which empirically determined parameters are an integral part of theory. Both aspects involve the reappraisal of the praxis of chemists, which reflects the commitments and methodological preferences of the community as a whole.

Nye has had to be very selective in her choice of case studies. Other choices might even have provided counterarguments to parts of her thesis. Nevertheless, the book is an intriguing attempt to contribute to the understanding of an extremely important and difficult theoretical problem in the history of the physical sciences, and, all in all, it is a success. $\square$

Kostas Gavroglu is a historian in the Department of Physics, Zogratu Campus, National Technical University, 15780 Athens, Greece.
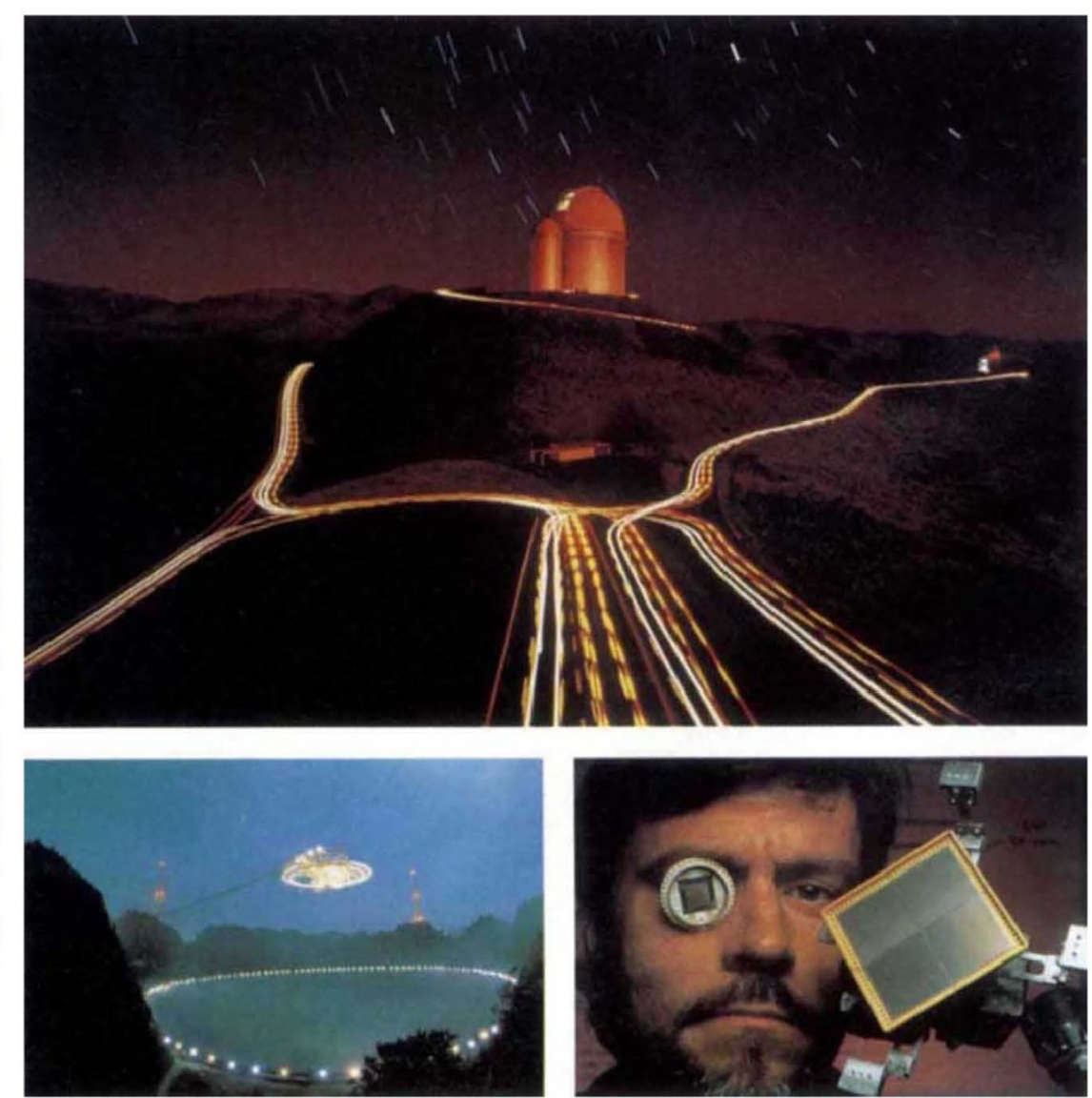

STAR shots: top, Chile's Southern Observatory; bottom left, the 305-meter Arecibo radiotelescope in Puerto Rico, which began searching for extraterrestrial life in 1992; right, astronomer Gerry Luppino eyes up a Hubble Space Telescope unit of 640,000 cells. The pictures won Roger H. Ressmeyer of National Geographic magazine first prize in the Science and Technology category of the 37th World Press Photo Contest held in 1993. Taken from World Press Photo Yearbook 1994 edited by Ben Ten Berge and Keri Lundelin. Thames and Hudson, $£ 9.95$ (pbk). 